\title{
Application of gray prediction and linear programming model in economic management
}

\author{
Shuli Song \\ Heilongjiang Bayi Agricultural University, Daqing 163319, China
}

Corresponding Author Email: 454673843@qq.com

https://doi.org/10.18280/mmep.050107

Received: 15 October 2017

Accepted: 12 January 2018

\section{Keywords:}

gray prediction, linear programming model, technical progress, investment benefit

\begin{abstract}
At present, the gray system theory has enjoyed immense popularity in the field of economy and management. From gray optimization, gray control to gray prediction, the results of the theory have been paid more and more attention and been applied extensively in the economic development and enterprise management. Aiming at constructing a gray linear programming model based on gray prediction and applying the model to enterprise operation and management, this paper forecasts the future technical progress of the enterprise through gray prediction and verifies the accuracy of the prediction. It is proved that the prediction has a high accuracy, indicating that the gray prediction model is applicable to the forecast of technical level. Besides, this paper establishes a linear programming model to analyze the investment income of different projects in an enterprise, thereby providing the basis for managers to make decisions.
\end{abstract}

\section{INTRODUCTION}

Since macroeconomic and management constitute a gigantic and complex system, it is of theoretical and practical values to study macroeconomic states and predict economic trends through quantitative economics measures and models [1]. However, the massive amount of data in the macroeconomic model makes it extremely difficult to take full account of all the economic relations [2]. This brings the demand for more effective utilization of existing human, material and financial resources in economic development and enterprise management with the aim of achieving more goals, which happens to be the main purpose of linear programming [3-4]. As a result, general linear programming has been widely applied in various areas of the society. The limitations in the general linear programming can be resolved to a certain extent by the linear programming based on gray prediction [5-6].

Gray prediction system analysis is a novel set of concepts and methods developed on information incompleteness [7-8]. The analysis is targeted at predicting the unknown information about the system through a mathematical model established on the known information. Scholars at home and abroad have done a lot of research on gray system analysis [9-11]. So far, gray prediction linear programming has been applied in an increasingly broad range, covering economics, management and a variety of other aspects of the society. Against this backdrop, this paper mainly tries to establish a linear programming model based on gray prediction and apply it in in enterprise operation and management.

\section{CONSTRUCTION OF GRAY PREDICTION CALCULATION MODEL}

GM $(1,1)$ is the most commonly used gray prediction model. It is made up of a first-order differential equation with only one variable [12-14].
Let there be an original data column with the variable $\mathrm{x}^{(0)}$ :

$\mathrm{x}^{(0)}=\left\{\mathrm{x}^{(0)}(1), \mathrm{x}^{(0)}(2), \ldots, \mathrm{x}^{(0)}(\mathrm{n})\right\}$

Generate first-order accumulated generation module $\mathrm{x}(1)$ with AGO:

$\mathrm{x}^{(1)}=\left\{\mathrm{x}^{(1)}(1), \mathrm{x}^{(1)}(2), \ldots, \mathrm{x}^{(1)}(\mathrm{n})\right\}$

Establish a differential equation based on the first-order gray module $\mathrm{x}^{(1)}$ :

$\frac{d x^{(1)}}{d t}+\alpha x^{(1)}=b$

Thus, we get:

$x^{(1)}(k+1)=\left[x^{(1)}(1)-\frac{b}{a}\right] e^{-a k}+\frac{b}{a}$

Rewrite the equation in the discrete form:

$x^{(1)}(k+1)=\left[x^{(1)}(1)-\frac{b}{a}\right] e^{-a k}+\frac{b}{a}$

where

$$
\begin{gathered}
=\left[\begin{array}{c}
x_{1}^{(0)}(2) \\
x_{1}^{(0)}(3) \\
\ldots \\
x_{1}^{(0)}(n)
\end{array}\right], \mathrm{B}=\left[\begin{array}{l}
a \\
b
\end{array}\right], \mathrm{X}=\left[\begin{array}{ll}
-\frac{1}{2}\left[x_{1}^{(1)}(1)+x_{1}^{(1)}(2)\right. & 1] \\
-\frac{1}{2}\left[x_{1}^{(1)}(2)+x_{1}^{(1)}(3)\right. & 1] \\
\cdots & \cdots \\
-\frac{1}{2}\left[x_{1}^{(1)}(n-1)+x_{1}^{(1)}(n)\right. & 1]
\end{array}\right] \\
\mathrm{B}=\left(X^{T} X\right)^{-1}\left(X^{T} Y\right)=\left[\begin{array}{l}
a \\
b
\end{array}\right] .
\end{gathered}
$$

The predicted value obtained by the prediction model is $\hat{x}^{(1)}(k+1)$. To determine the accuracy of the prediction, it is 
necessary to carry out a statistical testing. There are mainly two posterior differential test criteria:

The first one is the difference ratio $\mathrm{C}$, which is the ratio of residual variance to data variance, i.e.:

$\mathrm{C}=\frac{S_{e}}{S_{x}}$

Where $S_{e}^{2}=\frac{1}{n} \sum_{j}^{n}\left[e^{(0)}(j)-\bar{e}\right]^{2}$ and $S_{x}^{2}=\frac{1}{n} \sum_{j}^{n}\left[x^{(1)}(j)-\bar{x}\right]^{2}$. The second one is the small error probability $\mathrm{P}, \mathrm{P}=$ $\mathrm{P}\left\{\left|e^{(0)}(K)-\bar{e}\right|<0.6744 S_{x}\right\}$.

According to the above two test methods, we can divide the prediction results into four levels. (Table 1)

Table 1. Division of prediction levels

\begin{tabular}{|c|c|c|}
\hline Level of prediction accuracy & C & P \\
\hline A. good & $<0.35$ & $>0.95$ \\
\hline B. qualified & $<0.5$ & $>0.8$ \\
\hline C. reluctantly & $<0.45$ & $>0.7$ \\
\hline D. unqualified & $\geq 0.65$ & $\leq 0.7$ \\
\hline
\end{tabular}

The relationship between input and output of production is usually expressed by production functions, of which the CobbDouglas function is the most widely used one [15-16]. It is expressed as:

$\mathrm{Y}=\mathrm{AL}{ }^{\alpha} \mathrm{K}^{\beta}$

where $\mathrm{Y}$ is the output, $\mathrm{K}$ is the capital input and $\mathrm{L}$ is the labor input. There are two ways to achieve expanded reproduction: first, keep the technical level of production unchanged, and expand production by investing more capital or labor; second, keep the reinvestment unchanged, stimulate the production by improvement in production quality. The second approach is called "technical progress".

Because the technical level of production is changing over time, the production function can be expressed as:

$\mathrm{Y}=\mathrm{F}(\mathrm{K}, \mathrm{L}, \mathrm{t})$

Where $\mathrm{K}$ and $\mathrm{L}$ can be regarded as function of $\mathrm{t}$. By taking the derivative of time, we can obtain:

$\frac{d Y}{d t}=\frac{\partial F}{\partial K} \frac{d K}{d t}+\frac{\partial F}{\partial L} \frac{d L}{d t}+\frac{\partial F}{\partial t}$

Substitute $\dot{Y}=\frac{d Y}{d t}, \dot{K}=\frac{d K}{d t}$ and $\dot{L}=\frac{d L}{d t} \mathrm{t}$ into Formula (7), and divide both sides of the equation by $\mathrm{Y}$. There is:

$\frac{\dot{Y}}{Y}=\frac{K F_{K}}{Y} \frac{\dot{K}}{K}+\frac{L F_{L}}{Y} \frac{\dot{L}}{L}+\frac{F_{t}}{Y}$

Where $F_{k}=\frac{\partial F}{\partial K}, F_{L}=\frac{\partial F}{\partial L}$ and $F_{t}=\frac{\partial F}{\partial t}$

It can been seen from the above equation that the input increases mainly thanks to: capital investment, labor increase and technical progress.

If we view $\frac{K F_{K}}{Y}$ and $\frac{L F_{L}}{Y}$ in Formula (8) as constants and denote them with $\alpha$ and $\beta$ respectively, the formula can be rewritten as:

$\frac{\dot{Y}}{Y}=\alpha \frac{\dot{K}}{K}+\beta \frac{\dot{L}}{L}+\frac{\dot{A}}{A}$ where $\frac{\dot{K}}{K}, \beta \frac{\dot{L}}{L}$ and $\frac{\dot{A}}{A}$ respectively stand for the contribution of capital, labor and technical progress to output.

If we rewrite Formula (9) in the differential form, and take the time increment as $\Delta \mathrm{t}=1$, we can obtain:

$\frac{\Delta Y}{Y}=\alpha \frac{\Delta K}{K}+\beta \frac{\Delta L}{L}+\frac{\Delta A}{A}$

Without considering the factor of technical progress, if the labor and capital have the same increase rate, there is:

$\frac{\Delta Y}{Y}=\alpha \frac{\Delta K}{K}+\beta \frac{\Delta L}{L}=(\alpha+\beta) \frac{\Delta K}{K}+(\alpha+\beta) \frac{\Delta L}{L}$

Next, the coefficient of technical progress is estimated. Since the production function $\mathrm{Y}=\mathrm{AL}^{\alpha} \mathrm{K}^{\beta}$, the marginal productivity is:

$F_{L}=\frac{\partial Y}{\partial L}=A K^{\beta} \alpha L^{\alpha-1}=\alpha \frac{Y}{L}$,

$F_{K}=\frac{\partial Y}{\partial K}=A \beta K^{\beta-1} L^{\alpha}=\beta \frac{Y}{K}$

$\mathrm{Y}=\mathrm{L} \frac{\partial Y}{\partial L}+K \frac{\partial Y}{\partial K}$

Multiple both sides of Formula (12) by the product price PY. There is: $P_{Y} Y=L\left(P_{Y} \frac{\partial Y}{\partial L}\right)+K\left(P_{Y} \frac{\partial Y}{\partial K}\right)$

Where PK and PL are the shadow price of capital and the shadow price of labor respectively. If $\mathrm{PK}=\mathrm{PL}$, there is:

$\mathrm{A}=\left(\frac{Y}{L}\right)^{\left(1-\frac{K}{Y}\right)}\left(\frac{K}{Y}\right)^{-\frac{K}{Y}}$

For verification of the practicality of the prediction model, we predict the coefficient of technical progress based on the time series of the technical level (A) of a Chinese enterprise in 2007-2015. Figure 1 shows the original data of the enterprise's technical level (A).

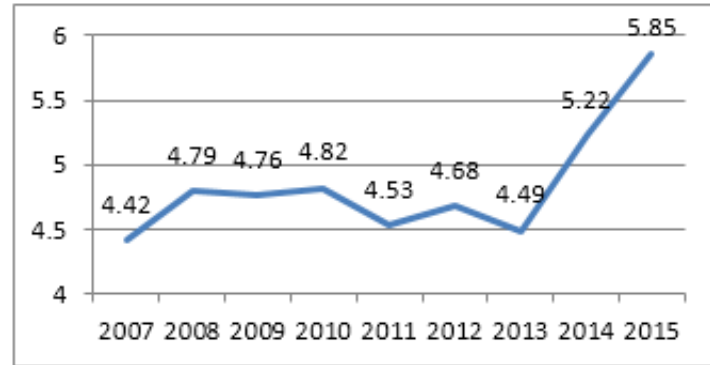

Figure 1. The original data of technical level (A)

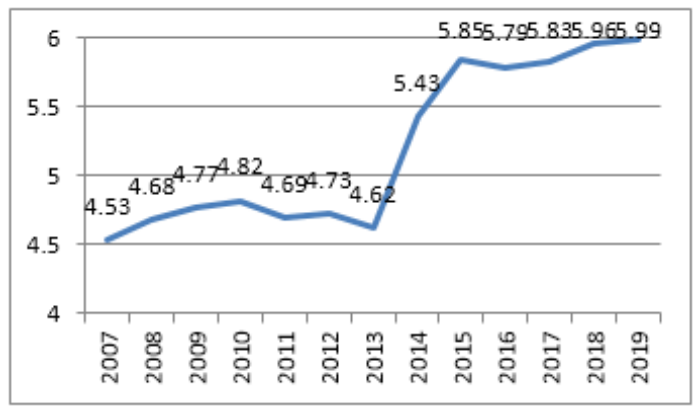

Figure 2. Predicted results of technical level (A) 
With the application of the GM $(1,1)$ model, we can obtain that $\mathrm{B}=(\mathrm{a}, \mathrm{b})^{\mathrm{T}}=(-0.027555,4.392743)^{\mathrm{T}}$.

Thus, the prediction model is: $\mathrm{A}^{(1)}(\mathrm{k}+1)=194.5364 \mathrm{e} 0.023548643 \mathrm{k}-192.4325$. Based on this model, we make a prediction of the technical level of the enterprise in 2007-2019 (Figure 2).

Then, the accuracy of the model is tested. Comparing the coefficients of the original data (Figure 1) and predicted results (Figure 2) on technical progress of the enterprise in 2007-2015, it is calculated that the posterior difference ratio $C=0.097<0.35$, indicating that the prediction has level 1 accuracy, and that the small error probability $\mathrm{P}=1.02>0.95$, which also proves that prediction accuracy reaches level 1 . Hence, the prediction by gray GM $(1,1)$ model is highly accurate and applicable to forecast of the technical progress of the enterprise.

As shown in Figure 2, we can see that the coefficient of technical progress (A) will keep rising at a rate of $2 \%$ in the coming years, and will reach 5.99 in 2019. For the enterprise, the development driven by capital and labor inputs will inevitably encounter bottlenecks. In contrast, technical progress is playing an increasing important role in promoting the development. Thus, more investment should be made in technical progress.

\section{ESTABLISHMENT AND APPLICATION OF LINEAR PROGRAMMING MODEL BASED ON GRAY PREDICTION}

(1)The concept of gray linear programming

Gray linear programming refers to any type of linear programming founded on the basis of gray prediction theories and methods. It is more scientific, advanced and practical than general linear programming. Its main features are: Firstly, the constraint value is time-variant; secondly, the model's coefficient changes in a certain range; thirdly, the objective function can be a relative optimization value, not necessarily an extreme value; finally, the model provides a lot of useful information and various options for making the final decision, leaving a high degree of freedom for decision-makers.

(2)The math model of gray linear programming

1. Objective function

$$
\mathrm{f}(\mathrm{x})=\oplus(\mathrm{C}) X^{T} \rightarrow \max (\text { or min })
$$

$$
\begin{aligned}
& \text { where } \oplus \text { is } \quad \text { the gray parameter, } \\
& \oplus(\mathrm{C})=\left[\oplus\left(C_{1}\right), \oplus\left(C_{, 2}\right), \ldots, \oplus\left(C_{n}\right)\right] \\
& \text { 2. Constraint: } \\
& \oplus(\mathrm{A}) \mathrm{X} \leq \oplus(\mathrm{B})^{\prime \prime} \\
& \mathrm{X} \geq 0
\end{aligned}
$$

where

$$
\begin{aligned}
& \oplus(\mathrm{A})=\left(\begin{array}{cccc}
\oplus\left(a_{11}\right) & \oplus\left(a_{12}\right) & \ldots & \oplus\left(a_{1 n}\right) \\
\oplus\left(a_{21}\right) & \oplus\left(a_{22}\right) & \ldots & \oplus\left(a_{2 n}\right) \\
\ldots & \ldots & \ldots & \ldots \\
\oplus\left(a_{m 1}\right) & \oplus\left(a_{m 2}\right) & \ldots & \oplus\left(a_{m n}\right)
\end{array}\right), \\
& \oplus(B)=\left[\oplus\left(b_{1}\right), \oplus\left(b_{2}\right), \ldots, \oplus\left(b_{m}\right)\right]
\end{aligned}
$$

(3)Predictive linear programming and its application

Predictive linear programming is often used in the investment decision-making process of an enterprise. For example, infrastructure program is the crux of the budget of an enterprise. This is because the funds of the enterprise are too limited to satisfy the unlimited growth of needs. Planners always favor a large number of infrastructure projects because of their importance both locally and globally. For decisionmakers, however, the limited funds should be used in the most needed areas rather than divert the funds evenly to every program. With economic benefit (investment recovery period and investment recovery rate) as the objective function and the investment limit as the constraint, we can find the solution of the linear programming, thus providing the most scientific basis for the decision makers of the enterprise.

A Chinese enterprise is taken as the example. The enterprise has RMB 1.2 million yuan of disposable capital, including RMB 300,000 yuan of administrative expenditure, RMB 260,000 yuan of wages and welfare funds, RMB 1.3 million yuan of the actual demand for liquidity in the current year, RMB 1.13 million yuan of production funds, RMB 170,000 yuan of infrastructure cost, RMB 530,000 yuan of tax, and RMB 470,000 yuan of the expected profit of production. Table 2 lists the total investment on infrastructure from 2010 to 2013.

Table 2. Capital investment time series

\begin{tabular}{|c|c|c|c|c|c|c|}
\hline year & 2010 & 2011 & 2012 & 2013 & 2014 & 2015 \\
\hline investment & 43.4 & 48.6 & 51.3 & 56.7 & $\mathrm{~b}_{5}$ & $\mathrm{~b}_{6}$ \\
\hline
\end{tabular}

In the current year, relevant departments suggest implementing 5 infrastructure projects. The investment plans are shown in Table 3. Operating income=current income(project consumption+depreciation); tax=the operating income $/ 2$; net income=operating income-tax; liquid capital=current income-project consumption-tax.

According to the above data, the following prediction programming model is established:

1. With optimal investment benefit as the objective function:

$\mathrm{f}=0.304 \mathrm{x}_{1}+0.456 \mathrm{x}_{2}+0.135 \mathrm{x}_{3}+0.242 \mathrm{x}_{4}+\oplus\left(x_{5}\right)$

$\rightarrow \max$

$\oplus \in[22.2,25.5]$ Take $\oplus=22.2$

2.Constraint equations (2014)

Investment:

$\mathrm{x}_{1}+\mathrm{x}_{2}+\mathrm{x}_{3}+\mathrm{x}_{4}+\mathrm{x}_{5} \leq \hat{\mathrm{b}}_{5}$

Project quota:

$0 \leq x 1 \leq 10,0 \leq x 2 \leq 30,0 \leq x 3 \leq 20,0 \leq x 4 \leq 30,0 \leq x 5 \leq 20$

Capital recovery:

$\frac{1.5}{10} \mathrm{x}_{1}+\frac{2}{30} \mathrm{x}_{2}+\frac{3}{20} \mathrm{x}_{3}+\frac{2.5}{30} \mathrm{x}_{4}+\frac{2.5}{20} \mathrm{x}_{5} \geq \mathrm{RMB} 60,000$ yuan

Demand of liquidity capital:

$\frac{4}{10} \mathrm{x}_{1}+\frac{4}{30} \mathrm{x}_{2}+\frac{13}{20} \mathrm{x}_{3}+\frac{10}{30} \mathrm{x}_{4}+\frac{6.5}{20} \mathrm{x}_{5} \leq \mathrm{RMB} 170,000$ yuan

3 . Predict $\hat{b}_{i}$ by GM $(1,1)$ based on gray prediction theory

Establish a numerical sequence $b_{0}$ according to the years of the infrastructure investment.

$\mathrm{b}_{0}=(43.4,45.651 .356 .7)$

Generate $b_{0}^{(1)}$, the first-order accumulated generation module of b0 with AGO, and construct the GM(1,1) model. Thus, we obtain the infrastructure investment model: $\hat{b}^{(1)}=400.134556 \mathrm{e}^{0.128197352 \mathrm{k}}+362.653809$

With the above formula, it is predicted that the infrastructure investment of 2014 and 2015 is respectively:

$\hat{\mathrm{b}}_{5}=67.5$ and $_{6}=72.3$

4. Solve the optimal solution (2014) with MATLAB5.3

$\mathrm{x} 1$ (Project A) = RMB 100,000 yuan;

$\mathrm{x} 2($ Project $\mathrm{B})=\mathrm{RMB} 300,000$ yuan;

$\mathrm{x} 3($ Project $\mathrm{C})=\mathrm{RMB} 0$ yuan;

$\mathrm{x} 4($ Project $\mathrm{D})=\mathrm{RMB} 100,600$ yuan;

$\mathrm{x} 5($ Project $\mathrm{E})=\mathrm{RMB} 132,400$ yuan . 
The target benefit (investment recovery): f=RMB 220,900 yuan (2014);

The average investment recovery rate $=22.09 \div 67.5=0.326$;

Repeat the above calculation process to obtain the prediction programming model for 2015 :

1. Objective function: $\mathrm{f}=0.304 \mathrm{x}_{1}+0.456 \mathrm{x}_{2}+$ $0.135 \mathrm{x}_{3}+0.242 \mathrm{x}_{4}+\oplus\left(x_{5}\right) \rightarrow \max$

$\oplus \in[22.2,25.5]$, Take $\oplus=22.2$

2. Constraint equations (2015)
Investment:

$\mathrm{x}_{1}+\mathrm{x}_{2}+\mathrm{x}_{3}+\mathrm{x}_{4}+\mathrm{x}_{5} \leq \hat{\mathrm{b}}_{6}$

Project quota:

$0 \leq \mathrm{x} 1 \leq 10,0 \leq \mathrm{x} 2 \leq 30,0 \leq \mathrm{x} 3 \leq 20,0 \leq \mathrm{x} 4 \leq 30,0 \leq \mathrm{x} 5 \leq 20$

Capital recovery: $\frac{1.5}{10} \mathrm{x}_{1}+\frac{2}{30} \mathrm{x}_{2}+\frac{3}{20} \mathrm{x}_{3}+\frac{2.5}{30} \mathrm{x}_{4}+\frac{2.5}{20} \mathrm{x}_{5} \geq$ RMB 60,000 yuan

Demand of liquidity capital: $\frac{4}{10} \mathrm{x}_{1}+\frac{4}{30} \mathrm{x}_{2}+\frac{13}{20} \mathrm{x}_{3}+\frac{10}{30} \mathrm{x}_{4}+$ $\frac{6.5}{20} \mathrm{X}_{5} \leq \mathrm{RMB} 170,000$ yuan

Table 3. Breakdown of infrastructure projects (Unit: RMB $10^{4}$ yuan)

\begin{tabular}{|c|c|c|c|c|c|}
\hline Project & Construction cycle & \multicolumn{2}{|l|}{ Investment } & Current income & Engineering consumption \\
\hline \multirow{4}{*}{ A } & 1 & & & 14 & 8.5 \\
\hline & 2 & & & 17.5 & 10 \\
\hline & 3 & & & 17.5 & 10 \\
\hline & 4 & & & 17.5 & 10 \\
\hline \multirow{5}{*}{$\mathrm{B}$} & 1 & & & 10 & 8 \\
\hline & 2 & & & 40 & 20 \\
\hline & 3 & & & 110 & 60 \\
\hline & 4 & & & 90 & 40 \\
\hline & 5 & & & 150 & 80 \\
\hline \multirow{2}{*}{$\mathrm{C}$} & 1 & \multirow{2}{*}{\multicolumn{2}{|c|}{20}} & 30 & 14 \\
\hline & 2 & & & 20 & 8 \\
\hline \multirow{4}{*}{$\mathrm{D}$} & 1 & \multicolumn{2}{|l|}{30} & 23 & 10.5 \\
\hline & 2 & & & 30 & 12.5 \\
\hline & 3 & & & 35 & 14.5 \\
\hline & 4 & & & 40 & 16.5 \\
\hline \multirow{5}{*}{$\mathrm{D}$} & 1 & & & 20 & 11 \\
\hline & 2 & & & 20 & 11 \\
\hline & 3 & & & 22 & 12 \\
\hline & 4 & & & 24 & 13 \\
\hline & 5 & & & 27 & 14 \\
\hline Project & Depreciation & Operating income & Tax & Net income & Liquid capital \\
\hline \multirow{4}{*}{$\mathrm{A}$} & 25 & 3 & 1.5 & 1.5 & 4 \\
\hline & 25 & 50 & 25 & 25 & 5 \\
\hline & 25 & 50 & 25 & 25 & 5 \\
\hline & 25 & 50 & 25 & 25 & 5 \\
\hline \multirow{5}{*}{$\mathrm{B}$} & 6 & (4) & (2) & (2) & 4 \\
\hline & 6 & 14 & 7 & 7 & 13 \\
\hline & 6 & 44 & 22 & 22 & 28 \\
\hline & 6 & 44 & 22 & 22 & 28 \\
\hline & 6 & 64 & 32 & 32 & 38 \\
\hline \multirow{2}{*}{$\mathrm{C}$} & 10 & 6 & 3 & 3 & 13 \\
\hline & 10 & 2 & 1 & 1 & 11 \\
\hline \multirow{4}{*}{$\mathrm{D}$} & 7.5 & 5 & 25 & 25 & 10 \\
\hline & 75 & 10 & 5 & 5 & 10.2 \\
\hline & 75 & 13 & 65 & 65 & 14 \\
\hline & 75 & 16 & 8 & 8 & 15.5 \\
\hline \multirow{5}{*}{$\mathrm{D}$} & 4 & 5 & 25 & 25 & 65 \\
\hline & 4 & 5 & 25 & 25 & 65 \\
\hline & 4 & 6 & 3 & 3 & 70 \\
\hline & 4 & 7 & 35 & 35 & 75 \\
\hline & 4 & 9 & 45 & 45 & 85 \\
\hline
\end{tabular}

Table 4. Investment and income of each project

\begin{tabular}{|c|c|c|c|c|c|}
\hline Item & $\mathrm{A}$ & $\mathrm{B}$ & $\mathrm{C}$ & $\mathrm{D}$ & $\mathrm{E}$ \\
\hline Investment requirements at the beginning of the year & 10 & 30 & 20 & 30 & 20 \\
\hline Net income in the first year & 1.5 & 2 & 3 & 1.5 & 2.5 \\
\hline Liquidity in the first year & 4 & 4 & 13 & 10 & 6.5 \\
\hline Fund recovery rate (\%) & 30.4 & 45.6 & 13.5 & 24.2 & $22.2-25.5$ \\
\hline
\end{tabular}

3. $\widehat{b}_{6}$ is predicted to be 72.3 by $\operatorname{GM}(1,1)$

4. Solve the optimal solution (2015) with MATLAB5.3

$\mathrm{x} 1($ Project $\mathrm{A})=$ RMB 100,000 yuan; $\mathrm{x} 2($ Project $\mathrm{B})=\mathrm{RMB} 300,000$ yuan;

$\mathrm{x} 3$ (Project $\mathrm{C})=\mathrm{RMB} 0$ yuan;

x4 (Project D) = RMB 216,380 yuan; 
$\mathrm{x} 5$ (Project $\mathrm{E})=\mathrm{RMB} 55,520$ yuan .

The target benefit (investment recovery): $\mathrm{f}=\mathrm{RMB} 231,900$ yuan (2015);

The average investment recovery rate $=23.19 \div 72.3=0.468$;

The calculated results show that: the investment benefit is higher in 2015 than in 2014 and the average investment return rate has increased by $3.23 \%$.

\section{CONCLUSIONS}

(1) Despite the extensive application in various fields of the society, the general linear programming still has many limitations. The problem can be resolved to a certain extent by the linear programming based on gray prediction, which is more scientific, advanced and practical than general linear programming. Firstly, the constraint value is time-variant; secondly, the model's coefficient changes in a certain range; thirdly, the objective function can be a relative optimization value; finally, the model provides a lot of useful information, leaving a high degree of freedom for decision-makers.

(2) GM $(1,1)$ is the most commonly used gray prediction model. This paper constructs a gray prediction model to predict the future technical progress of an enterprise. The accuracy test demonstrates that the proposed gray model has high prediction accuracy and can be used to forecast the technical progress of the enterprise. Besides, it is discovered that the enterprise will make more and more technical progress in the coming years.

(3) The gray linear programming model can be applied to economic development and enterprise management. The establishment of a predictive gray linear programming model helps predict and compare the programs proposed by different departments of the enterprise, so as to select the most suitable program for decision-makers.

\section{ACKNOWLEDGMENT}

The work was supported by Research project of philosophy and Social Sciences in Daqing (№. DSGB2017121).

\section{REFERENCES}

[1] Chen Z, Chen Q, Chen W, Wang Y. (2004). Grey linear programming. Kybernetes 33(2): 238-246.

[2] Liang RH. (1997). Application of grey linear programming to short-term hydro scheduling. Electric Power Systems Research 41(3): 159-165. https://doi.org/10.1016/S0378-7796(96)01128-5

[3] Li QX. (2007). The cover solution of grey linear programming. Journal of Grey System 19(4): 309-320.

[4] Tang W, Rao C, Li L. (2011). Grey linear programming problem of commodities' scheduling in large-scale emergency. Journal of Grey System 23(3): 281-290.

[5] Wang Z. (2013). Application of grey linear control theory for price regulation in china's real estate market. Kybernetes 42(3): 413-422. https://doi.org/10.1108/03684921311323662
[6] Xiao X, Lu Y. (2011). Grey linear regression model and its application. Kybernetes 41(5-6): 177-181. https://doi.org/10.1109/GSIS.2011.6044045

[7] Lang L, Chen JH, Zheng HL. (2012). Application of fuzzy grey predictability linear programming in capacity allocation of mine. Journal of Central South University 43(2): 611-619.

[8] Su CH, Liu SF. (2008). Asymptotic stability of grey stochastic linear delay systems. Kongzhi Yu Juece/control \& Decision 23(5): 571-574, 580.

[9] Grey A, Sekar A. (2008). Unified solution of securityconstrained unit commitment problem using a linear programming methodology. Iet Generation Transmission \& Distribution 2(6): 856-867. https://doi.org/10.1049/iet-gtd:20070367

[10] Guo P, Huang GH, Li YP. (2010). An inexact fuzzychance-constrained two-stage mixed-integer linear programming approach for flood diversion planning under multiple uncertainties. Advances in Water Resources 33(1): 81-91. https://doi.org/10.1016/j.advwatres.2009.10.009

[11] Liu Y, Huang G, Cai Y, Dong C. (2011). An inexact mix-integer two-stage linear programming model for supporting the management of a low-carbon energy system in china. Energies 4(10): 1657-1686. https://doi.org/10.3390/en4101657

[12] Fan YR. (2012). A robust two-step method for solving interval linear programming problems within an environmental management context. Journal of Environmental Informatics 19(1): 1-9.

[13] Li QX. (2014). The definition system and computational rule of grey determinant and its application to $\mathrm{n}$ grey equations with $\mathrm{n}$ grey linear equations. Grey Systems 2(1): 359 - 384. https://doi.org/10.1108/20439371211273258

[14] Cao DL, He CH, Li XF. (2008). Prediction of gdp in henan province based on a grey linear regression combined model. Journal of Henan Agricultural University 42(4): 469-472.

[15] Kose E, Forrest YL. (2015). N-person grey game. Kybernetes 44(2): 271-282. https://doi.org/10.1016/10.1108/K-04-2014-0073

[16] Ren A. (2015). A novel method for solving the fully fuzzy bilevel linear programming problem. Mathematical Problems in Engineering 2015(2): 1-11. https://doi.org/10.1155/2015/280380

[17] Xu B, Li N, Bai F. (2007). An interactive compensatory fuzzy algorithm for grey decentralized bi-level drifttype linear programming model. Systems Engineering 25(11): 91-96.

[18] Mosher SW, Densmore JD. (2005). Stability and monotonicity conditions for linear, grey, 0-d implicit monte carlo calculations. Transactions of the American Nuclear Society 93: 520-522.

[19] Su CH, Liu SF. (2008). Robust stability of grey neutral linear time-delay systems. Acta Mathematicae Applicatae Sinica 31(3): 520-527. 